POLLACK PERIODICA

An International Journal for Engineering and Information Sciences

DOI: $10.1556 / 606.2016 .11 .1 .1$

Vol. 11, No.1, pp. 3-12 (2016)

www.akademiai.com

\title{
NEW SIMPLE METHOD FOR THE ASSESSMENT OF MASONRY ARCH BRIDGES
}

\author{
${ }^{1}$ Zoltan ORBAN, ${ }^{2}$ Tamas JUHASZ \\ Department of Structural Engineering, Faculty of Engineering and Information Technology, \\ University of Pécs, Boszorkány u. 2, H-7624 Pécs, Hungary \\ e-mail:1'orbanz@mik.pte.hu,2 juhatom@gmail.com
}

Received 1 April 2015; accepted 22 June 2015

\begin{abstract}
The paper presents an approximation method for the assessment of the load carrying capacity of masonry arch railway bridges. The method is a simple semi-empirical tool for the initial level assessment that is considered to serve as a first sieve and provides conservative values for the load-carrying capacity and permissible axle load of single-span arches.

The proposed method is based on results obtained by the RING 2.0 masonry arch bridge analysis software. The method uses a closed mathematical formula to calculate the carrying capacity and its input parameters can easily be determined by simple site inspections or using data from bridge files.
\end{abstract}

Keywords: Masonry, arch, bridge, assessment

\section{Introduction}

Masonry arch bridges form an integral part of the railway infrastructure in Europe and throughout the world. They are the oldest structure types in the railway bridge population with thousands still in service. The number of masonry arch railway bridges and culverts is estimated to be around 200.000 individuals in Europe, which represents approximately $50 \%$ of the total railway bridge stock [1], making this type of bridge the most common one. For this reason, safe and reliable methodology should be used to assess the load carrying capacity of these bridges.

Assessment of masonry arch bridges is necessary for several reasons. The condition of arch bridges deteriorates with time, and accordingly their capacity to carry load also declines. To maintain the safety of the railway it is thus necessary to confirm that the 
load capacity of the arch is sufficient for the current and foreseeable applied loads without accelerated deterioration, and therefore that the arch remains serviceable.

The loading to which bridges are exposed may also change with time. Typically, axle loads, numbers of axles and vehicle speeds may increase, and when new train movements are proposed, it is necessary to confirm that the arches on the affected routes have sufficient capacity without eroding safety margins.

Assessment of masonry arch bridges is however a difficult task as their structural behavior depends on several parameters but there is little experience of the effect of changes in these parameters and masonry arches have internal elements that are extremely difficult to investigate. For that reason engineering judgment will remain to be an indispensable element of any arch assessment method. Particular issues over which judgment should be exercised are hidden details and the effects of existing damage to the arch.

In order to determine the adequacy of a particular arch structure with the minimum degree of effort and the highest reliability, the assessment should be carried out in levels of increasing refinement and complexity, starting with the initial level (Level 1) being based on the most conservative analytical assumptions. If the structure is shown to be inadequate in relation to the required load carrying capacity at this level, assessment work should continue, with subsequent levels seeking to remove conservatism in the assessment where this can be justified.

The process is cyclical in nature, each cycle being at an increasingly refined level until a decision on the adequacy of the bridge is reached. Conceptually it is useful to envisage levels of assessment according to the methods of analysis as follows [2]:

- Level 1: Simplest level using assumptions known to be conservative;

- Level 2: Use of more refined analysis and better structural idealization. This level may also include use of data on materials strengths based on recent material tests on another structure of similar form, materials and age;

- Level 3: Use of a bridge specific live loading based on a statistical model of the known traffic and/or the use of tests on materials samples or the use of load tests.

In this paper the authors gives an overview on the currently applied simple assessment tools for masonry arch bridges and make proposal for a new initial level semi-empirical assessment method.

\section{Existing simple assessment methods for masonry arches}

Before the $19^{\text {th }}$ century the design of masonry arch bridges was based on empirical and geometrical rules. Afterwards, elastic analysis was developed by Pippard [3] and Military Engineering Experimental Establishment (MEXE) [4] method was then used to assess the load carrying capacity of arch bridges. During the early and mid 60's, the plastic analysis was developed by Heyman [5] that led to a change in the way the behavior of masonry bridges is understand. Due to the computer revolution, several programs were developed based on Heyman's theorem. 


\subsection{The MEXE method}

The method is based on elastic principles where a two-pinned, parabolic arch static system is assumed to have a limited compressive strength of 13 tons/per square foot (cca. $1.4 \mathrm{~N} / \mathrm{mm}^{2}$ ). The load capacity is calculated using empirical formulas with the application of subjectively estimated modifying factors referring to the geometry and material condition of the bridge [3]. These modifying factors are determined principally by visual inspection of the bridge. Because of its simplicity and quickness the method is still widely used for the assessment of railway and highway masonry arches [1].

UIC Code 778-3R [2] gives guidelines for the use of the MEXE method. Experience and latest research show that in a large number of situations the method seriously underestimates the actual load-carrying capacity of the bridges. On the other hand in some other cases MEXE has been found to provide non-conservative results [6]. Other disadvantage is that the method is not transparent, which leads assessors to make assumptions without considering the real structural implications. The algorithm produces a 'black box' type answer i.e. there is no insight into the way how the input parameters influence the structural behavior.

\subsection{The mechanism method}

The conventional approach of the mechanism method assumes the limit load as the minimum load that activates a number of plastic hinges large enough to transform the arch to a mechanism [5].

Heyman's original method has been computerized and modified by several authors. These modifications were aimed to remove some of the limitations of the original method for example by accommodating infinite masonry crushing strength and horizontal soil pressures. One of the notable developments are discussed below.

The computerized method developed by M. Gilbert [7], [8] uses the upper-bound theory of plasticity in conjunction with geometrical compatibility criteria for the analysis of masonry arches. The software developed on the basis of the method is called RING [9].

According to the method the plastic collapse load of the structure can be obtained by minimizing the upper-bound solutions that form a kinematically admissible 'mechanism'. This means that failure can occur only with the formation of a sufficient number of hinges to form a mechanism. The solution is obtained from work equations using the theory of virtual works. A rigorous linear programming algorithm is used for solving the work equations. The model can accommodate special parameters like infinite masonry crushing strength, ring separation, interaction of spans in multispan bridges and the contribution of attached spandrel walls to the arch behavior. The sliding between adjacent blocks and rings are described by means of the 'plastic shearing' theory using Coulomb frictional law. A combination of bonded, frictional and frictionless interface conditions between the rings can be used to simulate partial ring separation. The algorithm was validated against a series of laboratory tests on model bridges [10]. 


\section{New simple assessment method for single-span arches}

An approximation method has been worked out for the assessment of masonry arch railway bridges. The method is considered a simple semi-empirical tool for the initial level assessment to serve as a first sieve and provide conservative values for the loadcarrying capacity and permissible axle load of arches.

The method uses a closed mathematical formula to calculate the carrying capacity and its input parameters can easily be determined by simple site inspections or using data from bridge files. The method can be used for single span semi-circular arches (Fig. 1 and Fig. 2) within the following variable parameter range:

- $2 \mathrm{~m} \leq L \leq 10 \mathrm{~m}$, where $L$ is the span of the arch;

- $0.05 \leq d_{\mathrm{c}} / L \leq 0.25$, where $d_{\mathrm{c}}$ is the thickness of the arch in the soffit;

- $0.5 \mathrm{~m} \leq h \leq 1.5 \mathrm{~m}$, where $h$ is the height of fill above the arch.

Arches with the above geometrical features represent the cast majority of railway masonry arch bridges in Hungary and Europe [1].

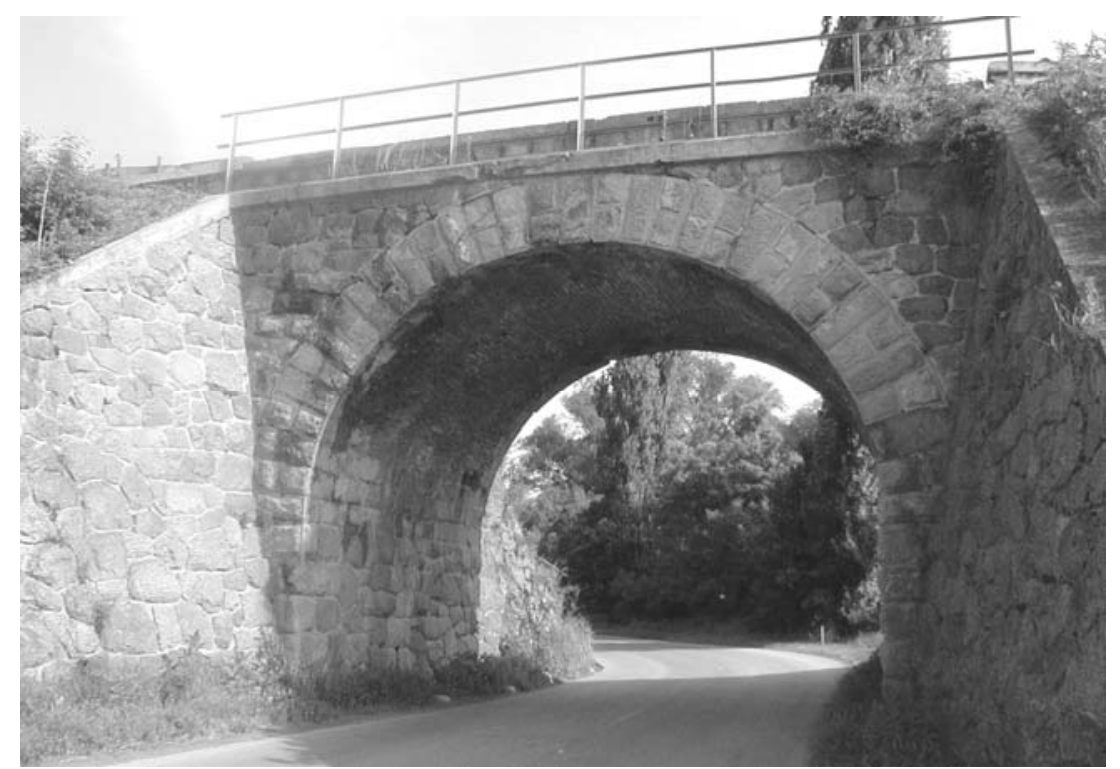

Fig. 1. Typical single span railway masonry arch bridge in Hungary

The method is based on results obtained by the RING 2.0 masonry arch bridge analysis software. In the calculations the arch barrel was assumed to be single ring arch with proper bonding between the masonry units. It was also assumed that the abutment provides sufficient vertical and horizontal resistance to the spread of the arch and there is no measurable movement at the springing of the arch under the action of live load. 
The effective width of the arch was set to a conservative value $(W=3.0 \mathrm{~m})$ that corresponds to a very minimal lateral load distribution below the sleepers.

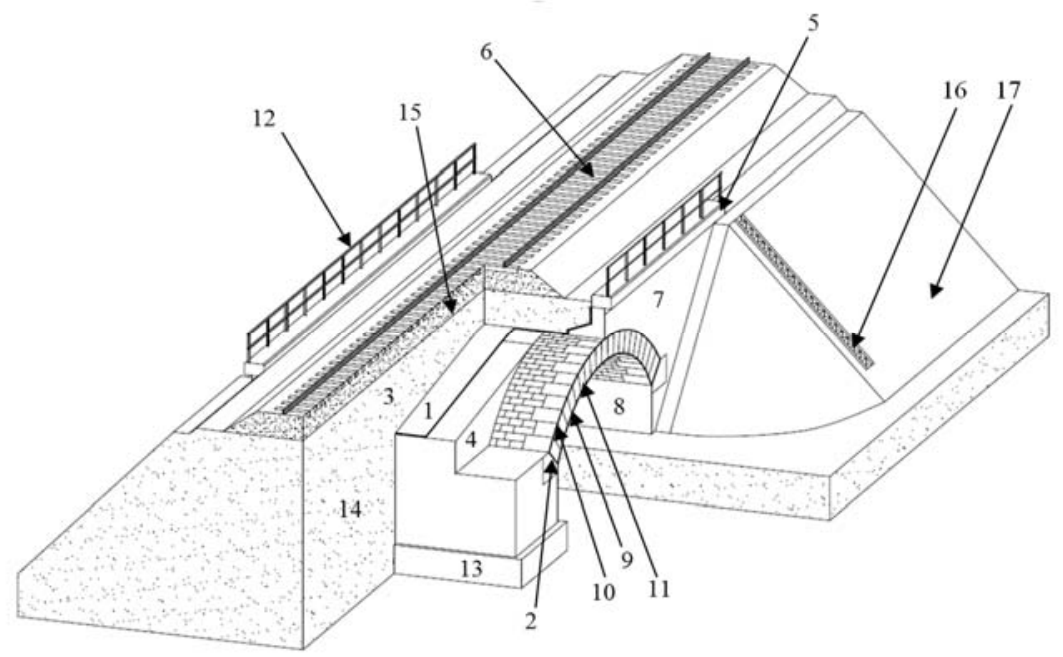

1-waterproofing; 2- springing; 3- fill; 4- backing/haunching; 5- edge beam; 6- railway track; 7- spandrel wall; 8- abutment; 9- intrados; 10- extrados; 11- arch stone; 12- railing;

13-foundation; 14- backfill; 15-ballast; 16-inspection stair; 17- substructure

Fig. 2. Elements of single span railway masonry arch bridge

The other input parameters were considered constants and based on conservative assumptions. These parameters are summarized as follows:

- Compressive strength of masonry in the arch, $f_{\mathrm{c}}=2 \mathrm{~N} / \mathrm{mm}^{2}$;

- The haunching and backing effects are ignored;

- The friction coefficient between the units, $\mu=0.6$;

- The backing has no cohesion, its internal angle of friction is $\phi=30^{\circ}$;

- The angle of load distribution in the ballast is $10^{\circ}$;

- The supporting effect of backfill is taken into account with a 1/3 multiplier for the passive earth pressure's coefficient;

- The arch is subjected to a 4 axle UIC71 load model [2]. It covers the effects of real train models;

- Other parameters are taken as default values given in the User's Guide of RING $2.0[9]$.

Some of the results of the calculations are given in Table I - Table III and Fig. 3, for $W=1 \mathrm{~m}$ effective width, in the practically important parameter ranges. The ultimate load is calculated for one axle in a 4-axle loading model. In Fig. 3 the distribution of the live load, the formation of a 4-hinged mechanism and the thrust line in the arch are demonstrated. 
Table I

The ultimate load of the arch $(\mathrm{kN})$ for $h=0.5 \mathrm{~m}$ height of fill and $W=1 \mathrm{~m}$ effective arch width

\begin{tabular}{|c|c|c|c|c|c|c|c|}
\hline$h=0.5 \mathrm{~m}$ & \multicolumn{7}{|c|}{$d_{\mathrm{c}} / L$} \\
\hline$L(\mathrm{~m})$ & 0.05 & 0.075 & 0.10 & 0.125 & 0.15 & 0.2 & 0.25 \\
\hline 2 & & & & & 548 & 880 & 1108 \\
3 & & & 305 & 460 & 675 & 1153 & 1420 \\
4 & & 245 & 375 & 555 & 790 & 1375 & \\
5 & & 288 & 435 & 635 & 895 & & \\
6 & 203 & 320 & 483 & 693 & 960 & & \\
7 & 225 & 355 & 528 & 750 & 1023 & & \\
8 & 245 & 375 & 555 & 780 & & & \\
9 & 260 & 398 & 578 & 808 & & & \\
10 & 278 & 423 & 608 & & & & \\
\hline
\end{tabular}

Table II

The ultimate load of the arch $(\mathrm{kN})$ for $h=1.0 \mathrm{~m}$ height of fill and $W=1 \mathrm{~m}$ effective arch width

\begin{tabular}{|c|c|c|c|c|c|c|c|}
\hline$h=1.0 \mathrm{~m}$ & \multicolumn{7}{|c|}{$d_{\mathrm{c}} / L$} \\
\hline$L(\mathrm{~m})$ & 0.05 & 0.075 & 0.10 & 0.125 & 0.15 & 0.2 & 0.25 \\
\hline 2 & & & & & 860 & 1380 & 1878 \\
3 & & & 415 & 613 & 868 & 1445 & 1953 \\
4 & & 305 & 463 & 670 & 935 & 1603 & \\
5 & & 340 & 515 & 738 & 1013 & & \\
6 & 233 & 368 & 548 & 780 & 1055 & & \\
7 & 250 & 395 & 583 & 820 & 1100 & & \\
8 & 263 & 410 & 603 & 833 & & & \\
9 & 275 & 425 & 623 & 863 & & & \\
10 & 290 & 448 & 650 & & & & \\
\hline
\end{tabular}

Table III

The ultimate load of the arch $(\mathrm{kN})$ for $h=1.5 \mathrm{~m}$ height of fill and $W=1 \mathrm{~m}$ effective arch width

\begin{tabular}{|c|c|c|c|c|c|c|c|}
\hline$h=1.5 \mathrm{~m}$ & \multicolumn{7}{|c|}{$d_{\mathrm{c}} / L$} \\
\hline$L(\mathrm{~m})$ & 0.05 & 0.075 & 0.10 & 0.125 & 0.15 & 0.2 & 0.25 \\
\hline 2 & & & & & 1160 & 1705 & 2153 \\
3 & & & 558 & 813 & 1113 & 1663 & 2150 \\
4 & & 375 & 570 & 813 & 1105 & 1680 & \\
5 & & 398 & 598 & 848 & 1133 & & \\
6 & 253 & 410 & 613 & 855 & 1143 & & \\
7 & 263 & 425 & 628 & 875 & 1155 & & \\
8 & 275 & 435 & 640 & 888 & & & \\
9 & 288 & 450 & 655 & 905 & & & \\
10 & 300 & 465 & 678 & & & & \\
\hline
\end{tabular}

Formula (1) gives an approximation function for the results obtained by the RING calculations. This approximation is made in such a way to provide conservative values in all cases

Pollack Periodica 11, 2016, 1 

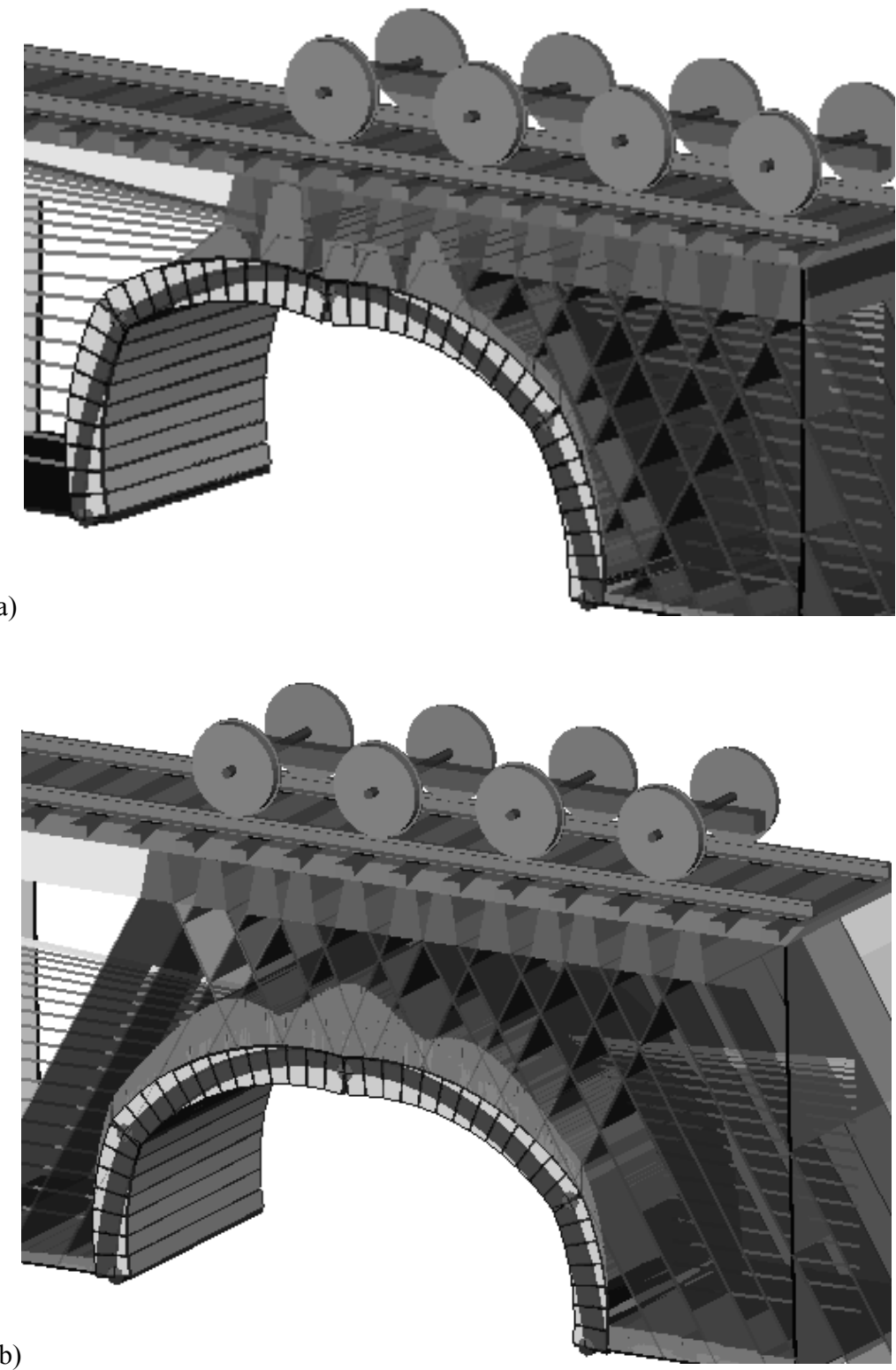

Fig. 3. The most unfavorable location of a four axle vehicle for different height of fill (h) values; a) $h=0.5 \mathrm{~m}$; b) $h=1.5 \mathrm{~m}$

$$
F_{t}=\cdot\left[A \cdot\left(\frac{d_{c}}{L}\right)^{k}(L-B)+C \cdot\left(\frac{d_{c}}{L}\right)\right], \mathrm{kN} / \mathrm{m},
$$


where: $F_{t}$ is the ultimate load of the arch calculated for $1 \mathrm{~m}$ width; $L$ is the span of the $\operatorname{arch}(2.0 \mathrm{~m} \leq L \leq 10 \mathrm{~m}) ; d_{c}$ is the thickness of arch in the soffit $(\mathrm{m}) ; A=2100-600 \cdot h$; $k=1.5+0.2 \cdot h ; B=10 \cdot h-2.5 ; C=1000 \cdot h ; h$ is the height of fill above the arch in meter dimension $(0.5 \mathrm{~m} \leq h \leq 1.5 \mathrm{~m})$.

As an example the results calculated with the approximation function (1) are represented in Fig 4 as dotted lines, for $h=1.0 \mathrm{~m}$.

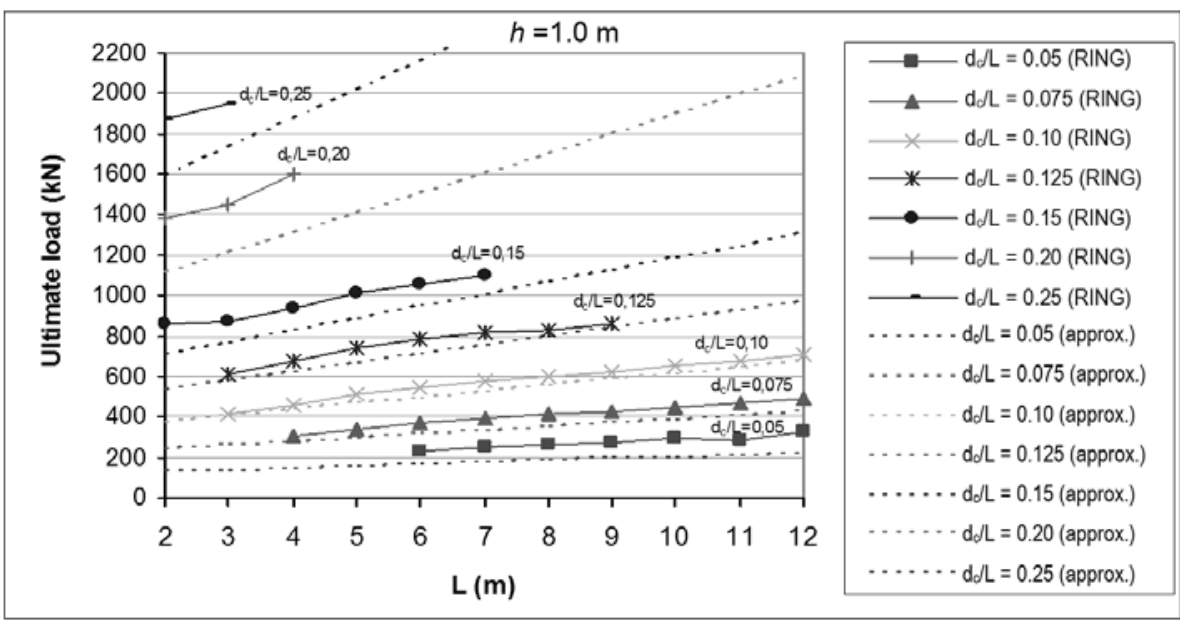

Fig. 4. The calculated and approximation values (dotted lines) of the ultimate load of the arch for $W=1 \mathrm{~m}$, in function of the $\operatorname{arch} \operatorname{span}(L)$, relative thickness $\left(d_{\mathrm{c}} / L\right)$ and height of fill $(h)$

Based on (1) the design value of the load carrying capacity can be given as:

$$
R_{d}=\eta \cdot \frac{1}{\gamma_{R}} \cdot \frac{1}{\mu} \cdot W \cdot\left[A \cdot\left(\frac{d_{c}}{L}\right)^{k}(L-B)+C \cdot\left(\frac{d_{c}}{L}\right)\right], \mathrm{kN},
$$

where $W$ is the effective width of the arch (recommended value: $W=3 \mathrm{~m}$ ); $\gamma_{R}$ is the global safety factor of the load carrying capacity $\left(\gamma_{R}=5\right.$ is recommended); $\mu$ is the dynamic factor for the vehicle by UIC Leaflet 776 - 1R:

$$
\mu=\Phi_{2}=\left[\frac{1.44}{\sqrt{2 L}-0.2}+0.82\right],
$$

and $\eta$ is a factor based on the damages of the arch according to Table $I V(0.8 \leq \eta \leq 1.0)$.

The validity range of the method is given in Table $I V$. If the arch has more serious damages than those defined in Table $V$ (e.g. diagonal cracks, separation of arch rings, 
etc.) the described approximation method cannot be applied. In these cases further site inspections and higher level assessment methods should be applied.

\section{Table IV}

Interpretation of the damage factor of the arch

\begin{tabular}{|l|c|}
\hline Condition / Description of damage & Damage factor, $\eta$ \\
\hline $\begin{array}{l}\text { The arch contains longitudinal cracks outside the middle } 3 \mathrm{~m} \text { effective } \\
\text { width. }\end{array}$ & $0.9-1.0$ \\
\hline $\begin{array}{l}\text { The arch contains longitudinal cracks inside the middle } 3 \mathrm{~m} \text { effective } \\
\text { width. }\end{array}$ & $0.8-0.9$ \\
\hline $\begin{array}{l}\text { The arch contains transversal cracks in the arch soffit inside the middle } \\
3 \mathrm{~m} \text { effective width. }\end{array}$ & 0.9 \\
\hline $\begin{array}{l}\text { There is a loss of joint material between the units or the surface of the } \\
\text { arch is weathered, but this damaged area does not exceed the 5\% of the } \\
\text { total arch thickness. }\end{array}$ & $0.9-1.0$ \\
\hline
\end{tabular}

Table V

The validity range of the approximation method

\begin{tabular}{|l|l|l|l|l|l|l|l|l|}
\hline $\mathrm{L}(\mathrm{m})$ & $2-3 \mathrm{~m}$ & $3-4 \mathrm{~m}$ & $4-5 \mathrm{~m}$ & $5-6 \mathrm{~m}$ & $6-7 \mathrm{~m}$ & $7-8 \mathrm{~m}$ & $8-9 \mathrm{~m}$ & $9-10 \mathrm{~m}$ \\
\hline $\mathrm{d}_{\mathrm{c}} / \mathrm{L}$ & $0.15-$ & $0.10-$ & $0.075-$ & $0.075-$ & $0.05-$ & $0.05-$ & $0.05-$ & $0.05-$ \\
& 0.25 & 0.25 & 0.20 & 0.15 & 0.15 & 0.15 & 0.125 & 0.125 \\
\hline $\mathrm{h}(\mathrm{m})$ & \multicolumn{10}{|c|}{$0.5 \mathrm{~m} \leq \mathrm{h} \leq 1.5 \mathrm{~m}$} \\
\hline $\begin{array}{l}\text { Damage } \\
\text { level }\end{array}$ & \multicolumn{10}{|c|}{ According to Table IV } \\
\hline
\end{tabular}

The verification of the load carrying capacity can be carried by out using formula (4), taking into account $\gamma_{\mathrm{E}}=1.2$ value for the global safety factor of the loading effect, or comparing the characteristic value of the actual axle load with the $Q_{a d m}=R_{\mathrm{d}} / \gamma_{\mathrm{E}}$ permissible value.

$$
R_{d} \geq E_{d}=E_{m} \cdot \gamma_{E},
$$

where $R_{d}$ is the design value of the load carrying capacity; $E_{m}$ is the mean value of the load effect; $E_{d}$ is the design value of the load effect; $\gamma_{E}$ is the global safety factor of the load effect.

\section{Conclusion}

A first level approximation method has been developed for the assessment of masonry arch railway bridges as an alternative to the widely used MEXE method.

The method gives a conservative estimation of the load carrying capacity and permissible axle load for semi-circular single span arches up to $10 \mathrm{~m}$ span. 


\section{Acknowledgements}

The presented scientific contribution is dedicated to the $650^{\text {th }}$ anniversary of the foundation of the University of Pécs, Hungary.

\section{References}

[1] Orban Z. Assessment, reliability and maintenance of masonry arch railway bridges in Europe, Proc. of ARCH'04, $4^{\text {th }}$ Int. Conf. on Arch Bridges, Barcelona, Spain, 17-19 November 2004, pp. 152-161.

[2] UIC Code 778-3R, Recommendation for the inspection, assessment and maintenance of masonry arch bridges, UIC International Union of Railways, 2011.

[3] Pippard A. J. S., Tranter E., Chitty L. C. The mechanics of the voussoir arch, J Inst Civil Eng, Vol. 4, 1936, pp. 281-306.

[4] Military engineering experimental establishment, classification of masonry arch bridges, Christchurch: Military Engineering Experimental Station, 1952.

[5] Heyman J. The masonry arch, Ellis Horwood, Chichester, United Kingdom, 1982.

[6] Wang J., Haynes J., Melbourne C. A comparison between the MEXE and Pippard's method of assessing the load carrying capacity of masonry arch bridges, ARCH 13, Proceedings of the 7th International Conference on Arch Bridges, Trogir, Croatia, 2-4 October, 2013, pp. 589-596.

[7] Gilbert M., Melbourne C. Rigid-block analysis of masonry structures, The structural Engineer, Vol. 72, No 21, 1994, pp. 356-361.

[8] Melbourne C., Gilbert M., Wagstaff W. The behavior of multi-span arch bridges, I. Int. Arch Bridge Conf, C. Melbourne (Ed), Thomas Telford, London, 1995, 489-497.

[9] RING 2.0 Masonry arch analysis software, http://www.limitstate.com/ring, (last visited 2 February 2015).

[10] Melbourne C., Gilbert M., Wagstaff M. The collapse behavior of multispan brickwork arch bridges, The Structural Engineer, Vol. 75, No 17, 1995, pp. 297-305. 